DOI: 10.17805/ggz.2017.6.6

\title{
«Бесплодные усилия любви» в русских переводах: опыт сравнительного анализа ${ }^{*}$
}

\author{
В. С. Макаров \\ Православный Свято-Тихоновский гуманитарный университет, г. Москва
}

В статье рассматриваются переводы ранней комедии Шекспира «Бесплодные усилия любви» (“Love's Labour's Lost”) на русский язык, созданные в XIX-XXI вв. Пьеса, с ее стилистическим и ритмическим разнообразием, а также большим количеством языковой игры, представляет значительную сложность для переводчика. Для сравнительного анализа переводов используются средства платформы Version Variation Visualization (VVV), русифицированная версия которой доступна nо адресу: www.shakespearecorpus.ru. Программа позволяет определить стратегии работы переводчиков с вызовами, которые им бросает шекспировский текст.

Ключевые слова: «Бесплодные усилия любви»; У. Шекспир; Шекспир в русских переводах; переводы; сравнительныли анализ; Version Variation Visualization; вариативность; переводческие стратегии

\section{“Love's Labour's Lost” in Russian Translations: An Attempt at Comparative Analysis}

\author{
V. S. Makarov
}

St. Tikhon's Orthodox University, Moscow

The article examines the problem of variation in the Russian translations of Shakespeare's early comedy "Love's Labour's Lost”. With its stylistic and rhythmical diversity, as well as a large amount of wordplay, the play presented a serious challenge for translators, in the 21st century no less than in the 19th. The comparative variation analysis is based on the segment-aligned presentation of the base text of the play and 7 Russian translations on the "Version Variation Visualization" platform (VVV), more specifically, its Russian localized version available at www.shakespearecorpus.ru. The variation analysis attempts to outline the strategies individual translators used and suggests a

\footnotetext{
* Статья подготовлена в рамках проекта «Разработка и внедрение в открытом доступе онлайнпрограммы сравнительного тезаурусного анализа русских переводов произведений У. Шекспира», осуществляемого при поддержке РФФИ (№ 17-04-12038в).

The article was prepared within the framework of the project "Development and Launching of Open Access Online Digital Tools for Comparative Thesaurus Analysis of Russian Translations of W. Shakespeare’s Works” with support from the Russian Foundation for Basic Research (nо. 17-04-12038в).
} 
re-evaluation of approaches to translation, regardless of their equilinearity, poetry / prose matching, and other qualitative factors, instead focusing on the communicative objectives of literary translations.

Keywords: “Love's Labour's Lost”; W. Shakespeare; Shakespeare in Russian translations; translations; comparative analysis; Version Variation Visualization; variation; translator's strategy

История русского художественного перевода - в значительной степени история борьбы за недостижимое совершенство, за единственно верную переводческую стратегию. В прошедшем столетии эта борьба чаще всего принимала форму бичевания «буквализма» ради «сотворчества» переводчика с автором. В исследовании А. Г. Азова (Азов, 2013) показано, насколько тесно полемика «буквалистов» (в первую очередь Е. Л. Ланна, Г. А. Шенгели) и «реалистов» школы И. А. Кашкина была связана с идеей «единственно правильного» метода, который наконец должен поднять переводчика до уровня автора. Можно вспомнить и то подозрение, с которым была встречена статья М. Л. Гаспарова о переводческом методе В. Я. Брюсова (Гаспаров, 1971), а в дальнейшем - его «экспериментальные переводы» (Гаспаров, 2003; см. также: Сонькин, Борисенко, 2010). Сейчас, когда споры о лучшем переводе перешли во многом на анекдотический уровень (чего, например, стоят рассуждения о том, что машинный перевод скоро сделает художественные переводы ненужными), полезно и важно отойти от самой соревновательности переводов - или вернее, оставить ее самим переводчикам и их читателям.

Одна из основных проблем самого спора о переводе - в том, что он обычно исходит из исключительности единственного приоритета: это может быть взгляд автора или взгляд переводчика как его читателя, но практически никогда - коммуникативная направленность на возможную аудиторию. Поскольку аудитория перевода неизбежно различается, особенно в свободно развивающейся культуре, где некоторым читателям нужен максимально близкий к оригиналу, академичный перевод, другим - свободное переложение или даже пересказ, третьим, возможно подстрочник, на основании которого они могли бы создать свой шекспировский «ремикс», четвертым - сценический перевод, в котором убрано все, что замедляет действие, дискуссия о переводах могла бы начаться с их классификации. «Сценические переводы», «переводы для чтения», «академические переводы» и т. д. могли бы занять каждый свою нишу на общем для всех поле. Это не означало бы, что в глазах читателя больше не будет «хороших» и «плохих» переводов. Всего лишь появилась бы некая «объективизированная» площадка, на которой все переводы, 
несмотря на различие в их коммуникативной направленности, в методе, близости к оригиналу, времени выполнения и т. п., формально бы фигурировали как равные.

Это помогло бы избежать еще двух, на мой взгляд, малопродуктивных подходов: во-первых, «окаменевания» классических переводов, за которым следует неизбежная и резкая «демифологизация» (как это произошло с маршаковскими переводами «Сонетов» Шекспира ${ }^{1}$ или период «застоя», когда новые переводы мыслятся только как вызов классическому. Во-вторых, речь о поиске неких общих ментальных (нередко философских) оснований для того или иного подхода к переводу вместо того, чтобы интерпретировать их как своеобразный акт коммуникации между переводчиком и его читателями, с присущими этому акту переводческими установками.

Возможность такого «равного положения», на мой взгляд, может дать компьютерная платформа, на которой полные тексты и переводов или их фрагменты были бы связаны с единым базовым текстом. Для данного проекта таким инструментом стала платформа Version Variation Visualization ${ }^{2}$, разработанная интернациональным британско-немецко-польским коллективом, а в теоретическом аспекте - концепция «перевода заново» (retranslation), постепенно входящая в круг важных проблем художественного перевода (см., например: Jianzhong, 2003; Paloposki, Koskinen, 2004; Brownlie, 2006).

Идея «перевода заново» основывается на том, что, какова бы ни была степень влияния предыдущего перевода того же текста, нельзя полностью исключить влияние (притяжение или отталкивание) тех, кто переводил этот текст ранее. Само по себе влияние часто недоказуемо, но можно измерить вариацию (т. е. отличие лексическое, синтаксическое и т. п.) между двумя или несколькими переводами (см. подробнее: Cheesman et al., 2017). К сожалению, пока возможности платформы ограничены - она измеряет лишь лексическую вариативность, причем успешно - на примере языков с ограниченным числом грамматических форм одного и того же слова (прежде всего английского и немецкого). Апробация VVV на материале русской литературы (как в нашем проекте) или комбинации иврита и английского, как в недавнем проекте Т. Чизмана (см.: Cheesman, Roos, 2017: Электронный ресурс) может дать новые, интересные результаты - но лишь в том случае, если будут соблюдены два условия: 1) представлен весь охват переводов по историческим периодам и коммуникативной цели и 2) тексты переводов представ-

\footnotetext{
${ }^{1}$ Например, в хорошо известной статье: Гаспаров, Автономова, 2001.

${ }^{2}$ Корпус русских переводов Шекспира размещен на сайте по адресу www.shakespearecorpus.ru, оригинальная версия программы - www.delightedbeauty.org/vvv/. Приношу благодарность доктору Тому Чизману и Кевину Флэнегену (Великобритания) за помощь в работе с платформой.
} 
лены полностью. Как показывает опыт (см. об этом ниже, в разделе о машинных переводах), определенная вариативная стабильность (т. е. сохранение значений показателя $\mathrm{Viv}^{3}$ с минимальным отклонением в 0,1-0,2 единицы) присутствует лишь в том случае, когда фрагменты сравниваются с фрагментами или полный текст с полным текстом. При всей важности и показательности определенных фрагментов для перевода всей пьесы (например, третьей сцены первого акта «Отелло» в проекте Т. Чизмана) окончательную уверенность в том, что вариативность измерена правильно, может дать только представление полного текста пьесы в сегментированном и соединенном с базовым текстом виде.

Таким образом, задачи нашего проекта включают анализ не только индивидуальных переводческих стратегий (такой анализ возможен, если последовательно сравнивать вариативность (показатель Viv) переводов разных пьес, выполненных одним переводчиком). Интересно проанализировать, и как вариативность будет коррелировать с основными жанровыми группами шекспировских пьес - комедиями, трагедиями, «проблемными пьесами», историческими хрониками, поздними трагикомедиями, в частности, насколько вариативность зависит от стилистического разнообразия.

\section{«НА ПИРУ ЯЗЫКОВ»: КОМЕДИЯ «БЕСПЛОДНЫЕ УСИЛИЯ ЛЮБВИ»}

Как одному из подготовителей академического комментированного издания ранней шекспировской комедии «Бесплодные усилия любви» (ок. 1594) в серии «Литературные памятники» издательства «Наука», автору данной статьи показалось чрезвычайно интересным сравнить ее существующие русские переводы для выявления вариативности. В качестве базового текста, как и для всего проекта «Программа сравнительного тезаурусного анализа русских переводов произведений У. Шекспира» было взято Фолджеровское издание (Shakespeare: Электронный ресурс) - как представленное в современной орфографии и компромиссное в отношении редакторских решений. Русские переводы взяты по возможности из последних прижизненных изданий ${ }^{4}$ (рис. 1).

3 O показателях Eddy и Viv см. подробнее на странице проекта: www.delightedbeauty.org/ vvv/Home/Project (Cheesman, Flanagan, Thiel, 2013: Электронный ресурс).

${ }^{4}$ Шекспир, 1873, 1894, 1899, 1937, 1945, 1958. Перевод С. А. Крынского (2016) приведен по авторской рукописи и с разрешения автора. 


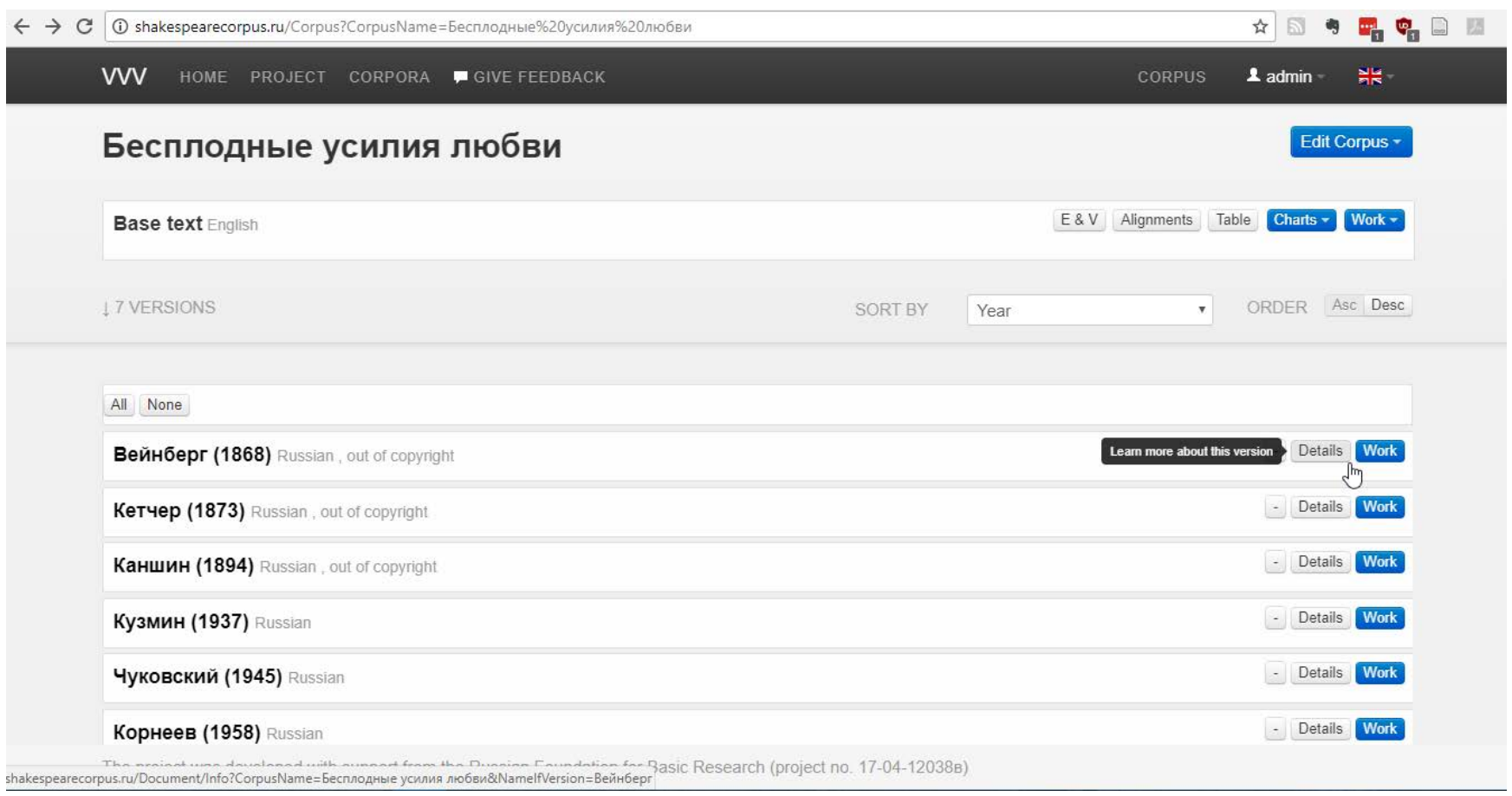

Рис. 1. Корпус русских переводов «Бесплодных усилий любви»: заглавная страница

«Бесплодные усилия любви» - комедия со сложной текстуальной историей (см. подробнее: Love's Labour's Lost ..., 2017: 449-461). Первому дошедшему до нас кварто (1598), как полагают ученые, предшествовало «нулевое», часть ошибок из которого перекочевала в первое кварто и была затем исправлена в Первом фолио (1623). Наличие в пьесе четырех пар влюбленных (Наваррский король и его придворные и французская принцесса со своими фрейлинами) с самого начала создало некоторую путаницу и невозможность одинаково глубоко прописать все характеры. Следствием этого стали такие проблемы текста, как «путаница Катерины и Розалины», когда часть реплик в разных изданиях приписывается то одной, то другой фрейлине (см.: Draudt, 1982), а также повторяющиеся реплики (особенно это заметно в V, 2, где Розалина дважды отправляет Бирона ухаживать за безнадежно больными; см.: Kerrigan, 1982ab). Вероятно, в попавшей к наборщикам рукописи старый, более короткий фрагмент, был заменен на более подробный на отдельном листе - но по ошибке (или не желая брать на себя ответственность), они набрали оба.

Следует сразу отметить, что несмотря на разные подходы переводчиков к проблемным местам текста (М. А. Кузмин, Ю. Б. Корнеев и С. А. Крынский работали с более новыми изданиями и соответственно пропускали повторы), на вариативность это не повлияло (что нормально в ситуации, когда реплика целиком про- 
пущена). Проблему Розалины и Катарины эти три переводчика также попытались решить логически, перераспределив реплики так, как это удобно для понимания.

Главными проблемами перед началом работы представлялись локализация максимальной вариативности и ее диапазон. Предсказанная Т. Чизманом тенденция высокой вариативности в коротких афористичных строках, где переводчику необходимо напрягаться, чтобы адекватно передать смысл (особенно с учетом большей длины русских слов по сравнению с английскими) в целом присутствует и в русских переводах, но с некоторыми особенностями, на которых считаю необходимым остановиться подробнее.

«Бесплодные усилия любви» — комедия, полная фраз с двойным смыслом и постоянных «переключений» тональностей. Так, в первой же сцене, когда король и придворные обсуждают предполагаемый отказ Бирона подписать обет воздержания от любви, друг за другом следуют четыре рифмующиеся реплики - три по существу, а последняя (самого Бирона) - житейская и бессмысленная в данном контексте ${ }^{5}$.

В режиме Eddy \& Viv видно, что вариативность резко снижается в тот момент, когда Бирон переключает тональность на ироническую (рис. 2).

Ограничения системы при работе с русскими словами очевидны: «гусь» и «гусыночка» определяются как разные слова. Дает себя знать и отсутствие тезаурусного анализатора: если бы платформа могла оценивать в коэффициентном значении сходство семантики слов, то «близко» и «недалеко» получили бы низкое значение вариативности. Таким образом, реальная вариативность переводов этой реплики еще ниже, чем та, что представлена на рисунке $(0,767$ против 1,048 и 0,9 в предыдущих строках). Так как реплика Бирона совершенно не связана с контекстом, переводчики могли бы заменить ее на любую другую, но все они (кроме пропускающего почти все «словесные дуэли» К. И. Чуковского), переводят ее очень близко к тексту, и находят возможность уложить в строку и размер.

Практически любой случай быстрого обмена репликами повышает вариативность, как правило, за счет разного перевода нескольких ключевых слов.

${ }^{5}$ В базовом тексте:

KING

How well he's read to reason against reading.

DUMAINE

Proceeded well, to stop all good proceeding.

LONGAVILLE

He weeds the corn, and still lets grow the weeding.

BEROWNE

The spring is near when green geese are a-breeding. 


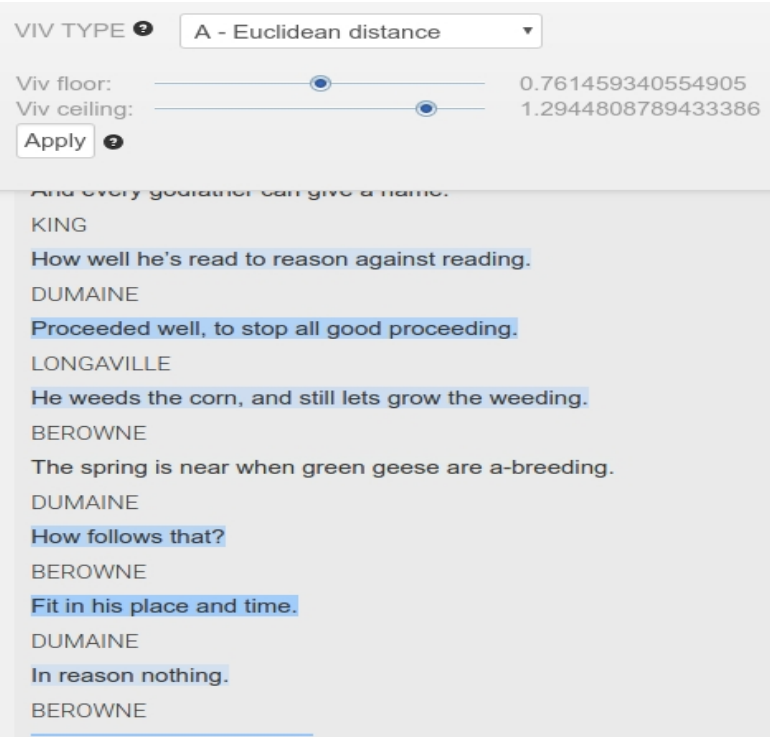

Рuc. 2. Режим Eddy \& Viv, «Бесплодные усилия любви» (I, 1).

Как показывает Т. Чизман, в таких случаях высокая вариативность помогает привлечь внимание исследователя «переводов заново» (и, разумеется, их переводчиков) к тем «узловым» словам, которые и создают разночтения (рис. 3).

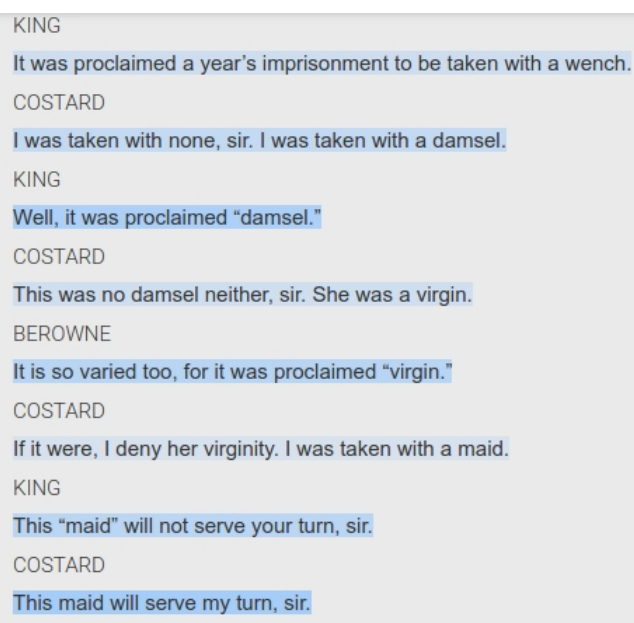

Рис. 3. Режим Eddy \& Viv, «Бесплодные усилия любви» (I, 2).

В этом случае, как и в предыдущих фразах, такими «узловыми словами» становятся обозначения разных категорий женщин в диалоге шута и придворных: «девица» - «девственница» - «девушка» - «дева»; «дама» - «барышня» «девица» - «девчонка» и т. д. Такой же эффект замечаем и в случае, когда фраза 
основана на разъяснении какого-то «узлового слова»: растолковывая фразу Армадо про "tender juvenal" (I, 2), почти все переводчики находят ему соответствие в прилагательном «нежный», но существительные, с которым оно согласуется, разные: «юноша» — «отрок» — «юнец» — «молодой человек» — «ювенал» (какой стилистический разнобой!)

Некоторые, особенно обладающие внутренней симметрией, фрагменты, в переводах неожиданно сильно варьированы (например, песни Весны и Зимы в V, 2 - показатель Viv соответственно 0,87 и 1,0). Такие фрагменты нуждаются в особенно глубоком анализе, проведение которого сейчас не входит в наши задачи.

Разумеется, в тексте есть и «информативные» (в терминологии Т. Чизмана) фрагменты, где низкая вариативность держится на протяжении нескольких строк (классический пример такого рода, приведенный самим Чизманом, - реплика из одного слова: «Яго!») В «Бесплодных усилиях любви» это, например, начало разговора комических персонажей о постановке процессии «Девяти мужей славы» $(\mathrm{V}$, 1). Предсказуемо высокой вариативностью отличаются фрагменты, где каждая реплика имеет двойной смысл (например, появление «московитов» и речь, которую по бумаге зачитывает паж, обращаясь к Принцессе и фрейлинам и якобы постоянно сбиваясь $(\mathrm{IV}, 1))$.

Корреляции между стихотворным размером и высокой вариативностью переводов, по предварительным наблюдениям, почти не замечено, кроме сверхкратких строк (3-4 слога). Проблема, тем не менее, заслуживает дополнительного анализа, так как строфика пьесы чрезвычайно богата.

Можно предположить, что в этом корпусе вариативность в целом будет больше, чем в пьесах, написанных строфически более ровно - исключительно в виде комбинаций пятистопного ямба и прозы. Предварительные наблюдения за статистикой других корпусов, работа над которыми ведется в этом году, подтверждают вывод, однако собранный материал пока недостаточен для серьезной гипотезы.

В целом все переводы, кроме выполненного для театральной постановки перевода К. И. Чуковского, максимально близко следуют расположению реплик в оригинале. Этому способствует то, что можно назвать «динамичным диалогом», характерным для шекспировской пьесы: многие сцены (особенно те, где действуют влюбленные) построены как быстрый обмен репликами в парах. В такой ситуации, если реплики теряются (например, у П. А. Каншина), то выпадают они тоже попарно. 
Отдельно следует сказать о переводческой стратегии К. И. Чуковского. Ориентируясь на сценичность и ясность реплик, он часто сокращает или удлиняет их (обычно с 1 строки до 2-3) по своему усмотрению, чтобы избежать невнятной сверхсжатости.

При просмотре в режиме «Соответствия» такие пропуски резко выделяются (рис. 4).

\section{Бесплодные усилия любви Alignment View}

Base text

Version Чуковский (1945)

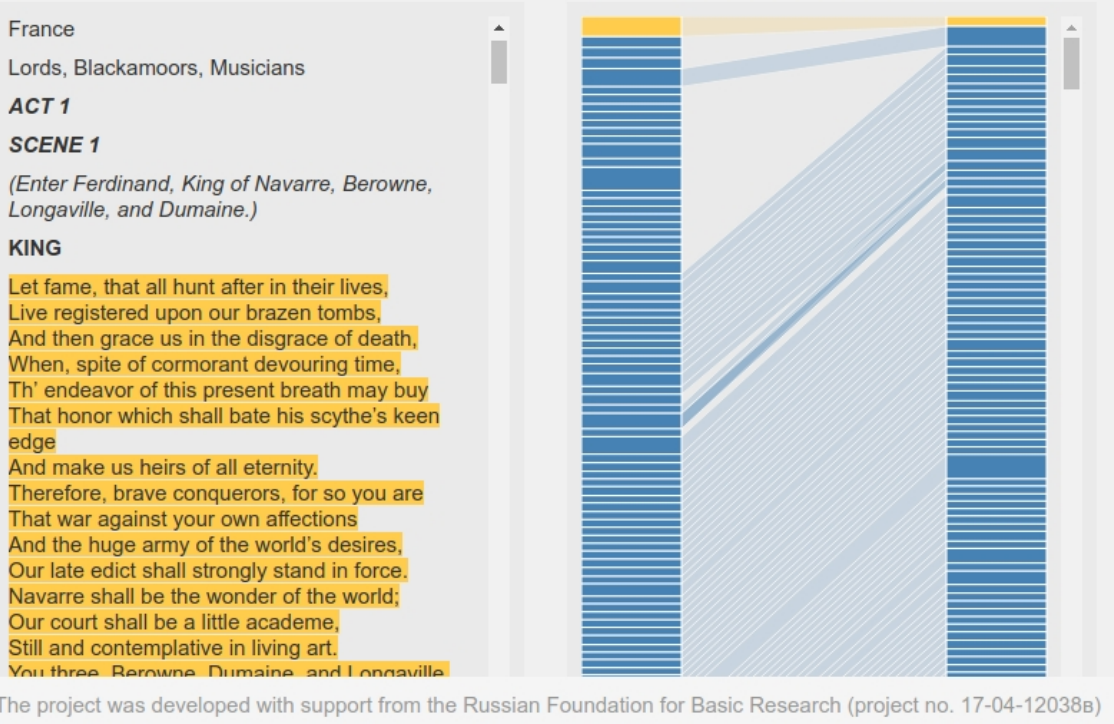

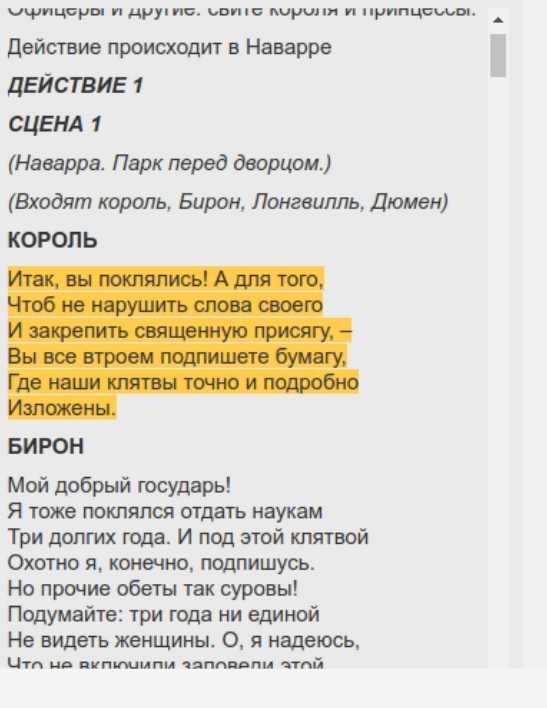

Рис. 4. Режим «Соответствия», пер. К. И. Чуковского $(I, 1)$

На иллюстрации перед нами очевидный пример сужения: 18 строк вступительной реплики Короля переведены пятью с половиной.

Есть и обратные примеры, причем не только те, где реплика расширяется, но и где она целиком придумана (рис. 5). Как правило, такая реплика у К. И. Чуковского носит моралистический характер. На рисунке прямоугольником выделена такая фраза Розалины. К сожалению, изобилие мелких реплик в комедии и отсутствие режима увеличения в средней колонке не позволяет увидеть, что сегмент справа (в переводе) не соединен ни с одним сегментом слева (в базовом тексте).

Стоит заметить, что убрав сцену с «Девятью мужами славы», К. И. Чуковский изменяет и суть признания Армадо. Комический герой признается уже не в том, что Жакнетта ждет от него ребенка, а в том, что он в нее влюблен. Тогда его решение три года «в поте лица добывать себе хлеб» (а не стать пахарем на три года, как в оригинале) уже не пародирует, а полностью повторяет новые 
обеты придворных. Похожие реплики К. И. Чуковский добавляет и в сцену перед появлением Меркада (Розалина: «О, этот маскарад да будет вам наукой...», Мария: «Останемся же попросту друзьями!») Хотя такое решение делает позицию героинь более четкой, зрителю, вероятно, трудно поверить, что эти читающие публичные нотации фрейлины могут действительно испытывать к наваррским придворным какие-то чувства.

Рис. 5. Режим «Соответствия», пер. К. И. Чуковского $(V, 2)$

\section{Бесплодные усилия любви Alignment View}

Base text

Sweet Majesty, vouchsafe me-

PRINCESS

Was not that Hector?

DUMAINE

The worthy knight of Troy.

ARMADO

I will kiss thy royal finger, and take leave. I am a

votary; I have vowed to Jaquenetta to hold the

plow for her sweet love three year. But, most

esteemed Greatness, will you hear the dialogue

that the two learned men have compiled in praise

of the owl and the cuckoo? It should have

followed in the end of our show.

KING

Call them forth quickly. We will do so.

ARMADO

Holla! Approach.

(Enter all.)

Thic sire is Hieme Winter. thic Vor the Snring

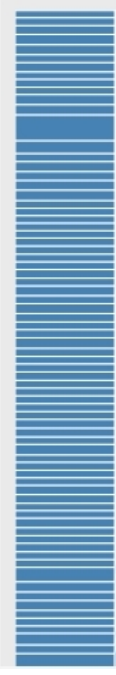

Version

Чуковский (1945)

Анализ графика вариативности подтверждает, что перевод К. И. Чуковского (темно-зеленый цвет на графике - рис. 6) значительно отстоит от всех остальных. Иногда это верно для целых фрагментов сцен (например, пикировка Бойе, Марии и Розалины в районе поз. 25000).

\section{МАШИННЫЙ ПЕРЕВОД ХУДОЖЕСТВЕННОГО ТЕКСТА: ЭКСПЕРИМЕНТ ПО ИЗУЧЕНИЮ ВАРИАТИВНОСТИ}

В традиционной переводоведческой парадигме машинный и художественный перевод - явления практически взаимоисключающие. Как верно указывают многие авторы, например, Ана Фернандес Гуэрра, для художественного перевода необходим человек с глубоким пониманием тонкостей языка (тот, кого Ф. Шлейермахер обозначал словом “ Übersetzer”; Fernández Guerra, 2000: 87-88), a 
в коммуникативном отношении художественный перевод эмотивен и всегда представляет собой сознательную интерпретацию (ibid: 16-17).

В схожем ключе Дирк Делабастита уточняет, что с коммуникативной точки зрения надо отличать «литературный» перевод (т. е. создание или воссоздание эстетического эффекта) от «литературного» текста (т. е. созданного изначально в расчете на такой эффект) (Delabastita, 2011: 69). Это уточнение позволяет найти нашему эксперименту место в типологии перевода - в итоге получается художественный текст, переведенный машинными (т. е. «нелитературными») средствами.

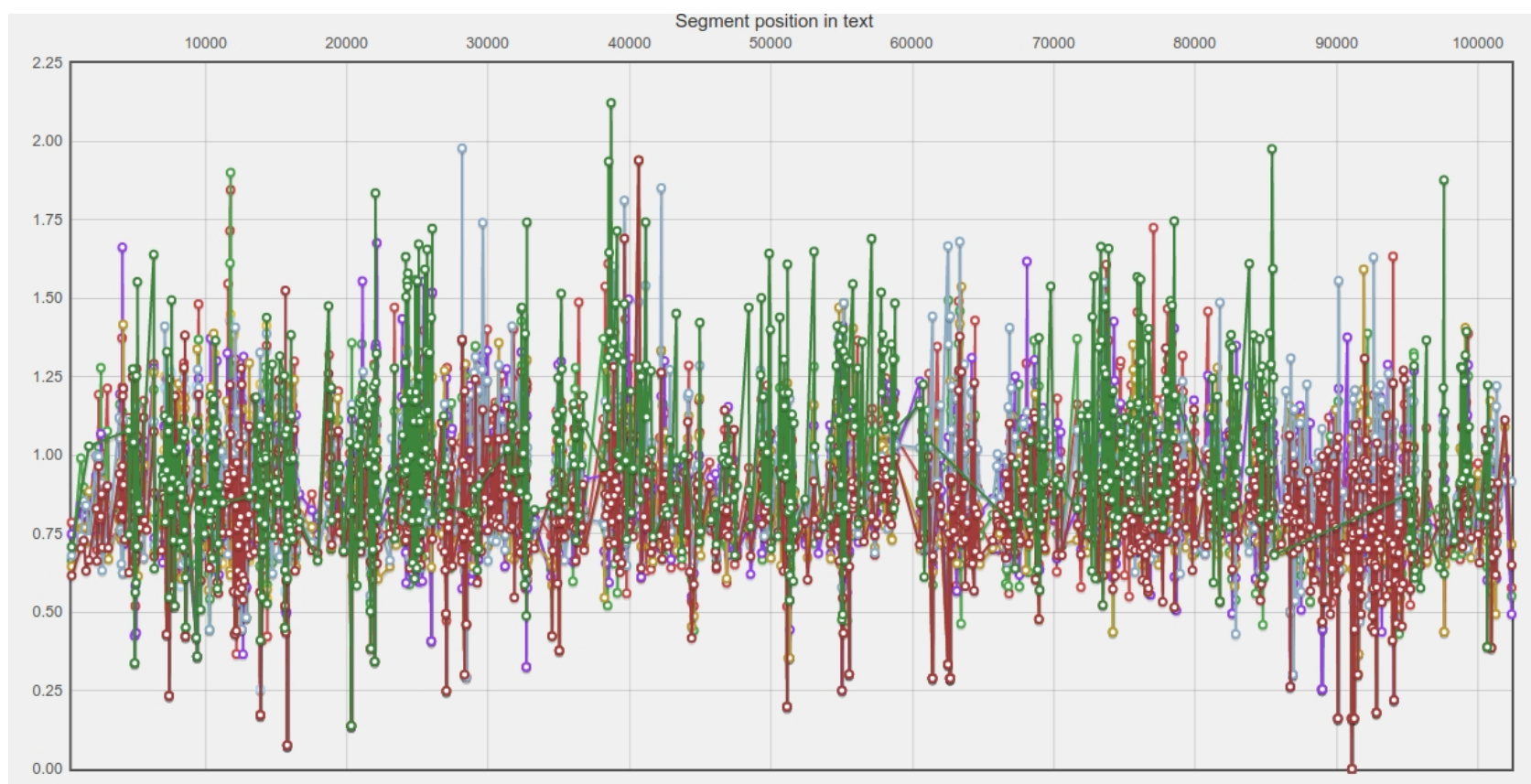

Рис. 6. Корпус «Бесплоднье усилия любви», режим «Вариативность».

Разумеется, по сравнению даже с самым слабым «дважды литературным» (по методу и тексту) переводом наш экспериментальный перевод будет смотреться невыигрышно. Но смысл эксперимента - не в том, чтобы сгенерировать перевод, способный состязаться за внимание читателя с творениями русских Übersetzer-oв, а в том, чтобы проверить, насколько велика будет вариативность в случае, когда:

- большая часть переводов выполнена литературно, т. е. с сознательным стремлением найти некоторый баланс между эстетическим воздействием и близостью к оригиналу;

- один или два перевода выполнены компьютерной программой, принципиально неспособной к производству эстетического воздействия.

Дополнительную трудность создает то, что сам по себе художественный текст хуже поддается машинному переводу, чем тексты других стилей. Основную 
причину этого исследователи видят в различных типах связности внутри текста (когезии) в литературном и нелитературном тексте (см.: Voigt, Jurafsky, 2012). Кроме того, существующую платформы машинного перевода не могут адекватно прослеживать синтаксис стихотворного текста - мешают знаки конца строки, особенно в случае анжамбеманов.

Чтобы не переформатировать базовый текст целиком, для эксперимента были выбраны концовка I, 1 (начиная с появления Башки/Репы с письмом от Армадо) и целиком сцена I, 2. Весь этот фрагмент, кроме стихотворного экспромта Мотылька, и еще нескольких строк, написан в прозе. Перед машинным переводом из текста были удалены сценические ремарки, указания на произносящего реплику персонажа. Стихотворные строки были преобразованы путем удаления символов конца строки. На сайте shakespearecorpus.ru тексты представлены в том виде, как получены от программы машинного перевода, с одним исключением - нормализованы имена героев, тем самым отчасти компенсируя «непонимание» машиной того, что она работает с художественным текстом.

Для эксперимента были выбраны две платформы машинного перевода Google Translate (https://translate.google.com) и Яндекс.Переводчик (https://translate. yandex.ru/). Обе платформы в настоящее время используют нейронные сети для анализа сегментов текста и сопоставления их с коллокациями, встречающимися в текстах авторов-людей.

Результат эксперимента показывает, что по вариативности оба фрагмента примерно соответствуют переводам XIX в. (см. о них в следующем разделе). Значительного отличия параметра вариативности не наблюдалось - хотя нужно учесть, что при сопоставлении неравных по длине корпусов возможны скачки вариативности. В зависимости от того, какие и сколько полных переводов включаются в выборку, два экспериментальных показывают Viv от 0,7 до 0,92. Единственное возможное объяснение — в их неполноте: показатель Viv ниже в том случае, когда в выбранных для сравнения переводах сцены I, 1 и I, 2 демонстрируют больше слов, опознаваемых как идентичные. Интересно, что относительно группы переводов ХІХ в. (Н. Х. Кетчер, П. А. Каншин и П. И. Вейнберг) положение экспериментальных фрагментов не изменяется, что, вероятно, означает значительное сходство в переводах второй части I, 1 и I, 2.

При просмотре в режиме Eddy \& Viv заметно, что экспериментальные фрагменты редко дают наибольшую или наименьшую вариативность. Их «нелитературный» метод работы с художественным текстом чаще всего помещает их в середину списка. При этом факт переводческой ошибки не всегда влияет на вариативность. Например, переводя реплику Армадо “Воу, what sign is it when a man of great 
spirit grows melancholy?" совершенно ошибочный вариант от Яндекса «Боже, что это за знак, когда человек великого духа тошнит?» имеет лишь слегка большую вариативность $(0,887$ против 0,833$)$, чем в целом чуть более правильный вариант от Google «Мальчик, какой знак, когда человек великого духа растет меланхолично?». Не очень большой диапазон вариативности в этом сегменте объясняется тем, что почти все переводчики задействуют слова «великого духа», «человек», «когда» и «знак».

Эксперимент, на наш взгляд, нуждается в продолжении. Как показала дискуссия во время презентации платформы на Ежегодной богословской конференции ПСТГУ, интересно было бы провести и еще один эксперимент: для каждого сегмента взять наименее вариативный текст из всех и таким образом (нормализовав при необходимости имена) получить «гипернормализованный перевод» - т. е. такой, в котором индивидуальные стили авторов будут нивелированы простым максимальным совпадением использованных слов. В дальнейшем мы планируем предложить фрагмент из гипернормализованного перевода в качестве слепого теста: как отреагируют на него читатели и любители Шекспира? Такая дискуссия помогла бы переключить внимание с субъективной проблемы качества перевода на более объективные вопросы индивидуального стиля и стратегий.

\section{КЛАССИФИКАЦИЯ РЕЗУЛЬТАТОВ И НЕКОТОРЫЕ ВЫВОДЫ}

Чрезвычайно важный для предварительных выводов режим «История» позволяет сгруппировать переводы не только по дате их выполнения, но и по очевидной коммуникативной стратегии переводчика (ось Y системы координат, где показана средняя вариативность - рис. 7).

На иллюстрации переводы довольно четко распадаются на 4 группы. В группе А объединены три дореволюционных перевода - полностью прозаические переводы Н. Х. Кетчера и П. А. Каншина и пытающийся дифференцировать стихотворные и прозаические строки перевод П. И. Вейнберга. Их нельзя назвать буквалистскими, но в целом их отличает прямолинейный подход к тексту, отсутствие претензий на сценичность, и установка на то, чтобы дать читателю в целом представление о комедии Шекспира. Это типичные "reading texts".

Группа В - два наиболее поэтически сильных перевода - М. А. Кузмина и Ю. Б. Корнеева - обладают и наименьшей вариативностью в этом ряду, причем как по отношению к своим предшественникам, так и последователям (С. А. Крынский). Их можно определить как “fine text”, задачей которого является баланс между точностью и поэтичностью. 
Перевод К. И. Чуковского (группа С) благодаря своей установке на использование в театре ("playtext”) стоит совершенно особняком.

Наконец, перевод С. А. Крынского (группа D) по вариативности в целом приближается к дореволюционным.

\section{Бесплодные усилия любви - Eddy history}

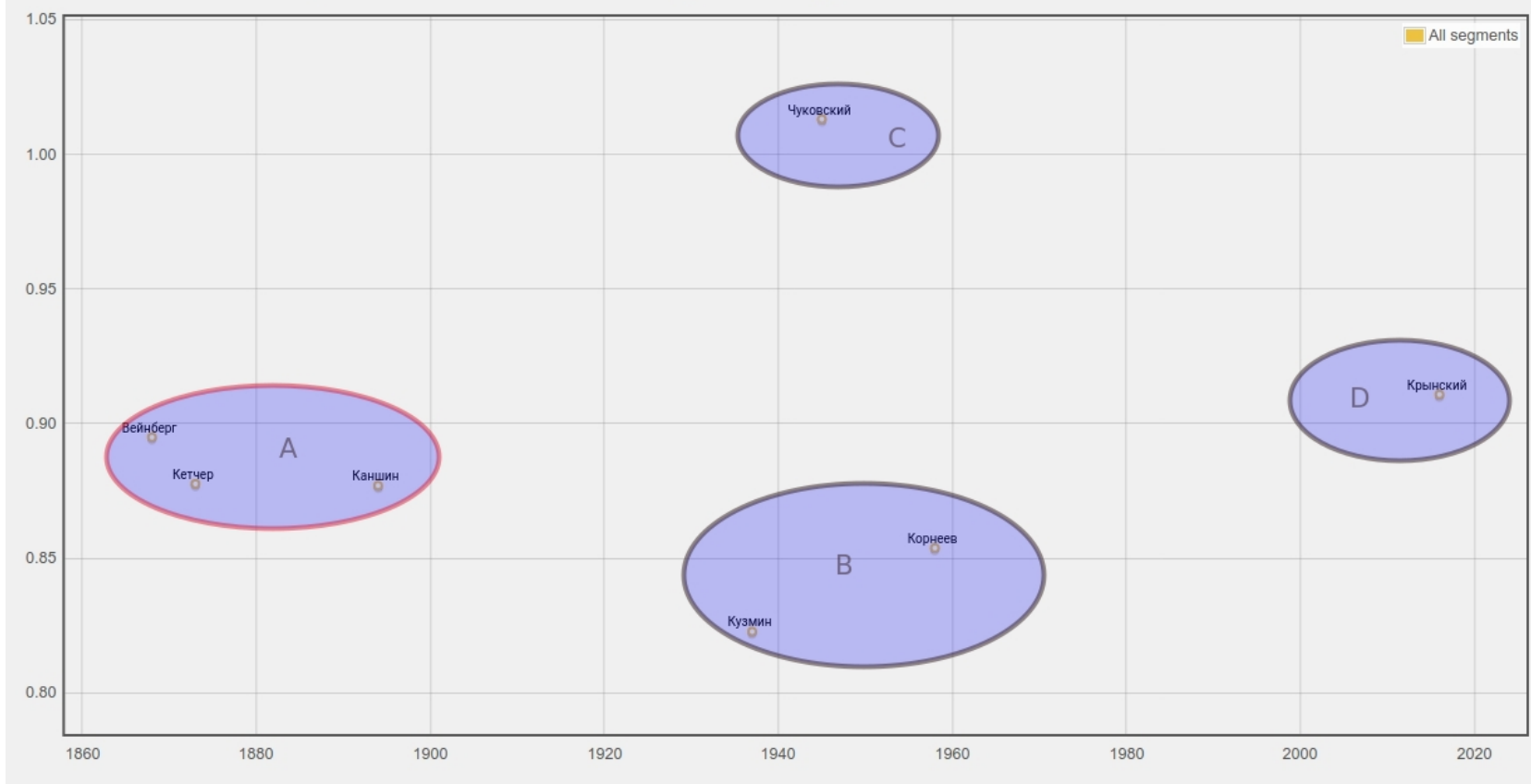

Рис. 7. Корпус «Бесплодные усилия любви», режим «История Eddy», экспериментальные фрагменты не включены

Эту картину можно уточнить и дополнить, если добавить в вычисление Viv:

a) соответствие не только самих текстов сегмента, но и произносящих их персонажей (такая опция уже присутствует на платформе, и возможно, будет внедрена в течение второго года проекта; очевидное препятствие - вариативность перевода самих имен персонажей: «Башка» — «Репа» (Costard), «Болван» — «Тупица» (Dull) и т. д.

б) возможность помечать сегмент как стихотворный либо прозаический. Очевидно, что в таком случае вариативность переводов П. А. Каншина и Н. Х. Кетчера (целиком прозаических) еще возрастет, а для тех переводов, где сложное шекспировское чередование стихов и прозы соблюдено - снизится. Однако неясно, насколько - при грамотном семантическом распознавании формы слова - такое деление на поэзию и прозу в принципе важно. Есть опасность, что оно смешает анализ вариативности с анализом точности, который отнюдь не является приоритетом для разработчиков платформы VVV. 
В целом, в сравнении с немецкими переводами «Отелло», диапазон вариативности крайне невелик: за исключением перевода К. И. Чуковского, он составляет всего 0,1. Предварительно можно объяснить это тем, что мы работали с книжными переводами, все из которых в той или иной степени ориентированы на точность. Переводы П. А. Каншина, М. А. Кузмина и Ю. Б. Корнеева были специально заказаны для собраний сочинений Шекспира и, очевидно, просматривались их научными редакторами. Во многом это верно и для Н. Х. Кетчера.

Разнообразить картину можно было бы, добавив в нее «шума» - театральных и других переложений комедии, но пока - кроме версии К. И. Чуковского таких текстов найти не удалось. Т. Чизман в работе с «Отелло» использовал аутентичные немецкие playtexts - театральные редакции литературных переводов; peдакции, в которые внесены сокращения, дополнения, требуемые сценографией определенной постановки.

В завершение этой нашей первой попытки анализа вариативности в русском корпусе шекспировских переводов обратимся к четырем гипотезам, высказанным Т. Чизманом после предварительного анализа массива немецких переводов сцены I, 3 «Отелло» (Cheesman et al., 2017: 753). Как мы видели выше, гипотеза 1 - о том, что афористические рифмованные двустишия представляют собой дополнительную трудность для переводчика с точки зрения формы - в целом подтверждается ${ }^{6}$. Однако еще большую сложность представляют краткие реплики после длинного монолога ${ }^{7}$, хотя семантически в них часто нет значительного отличия. Вероятно, их высокую вариативность надо отнести на счет краткости, которая заставляет переводчиков по-разному строить предложение даже из одинаковых слов.

Гипотеза 2 - о том, что вариативность выше в начале сцены или важного фрагмента - в целом не подтверждается, что можно объяснить субъективными расхождениями в понимании границ “major task" (коммуникативного фрагмента текста) или особенностями комедии «Бесплодные усилия любви».

Гипотеза 3 - о большей вариативности в локальных сегментах (т. е. имеющих более прагматически-коммуникативный, чем «глобальный», философский смысл) в значительной степени подтверждается - см. выше реплику Бирона о гусях.

И наконец, гипотеза 4 - о различной степени вариативности в переводах речей разных персонажей - пока не может быть проверена, т. к. на сайте shakespearecorpus.ru еще не проведены соответствия по этому типу данных.

\footnotetext{
${ }^{6}$ Например, реплика Короля: “These be the stops that hinder study quite, / And train our intellects to vain delight” (I, 1) — показатель Viv = 0,96.

${ }^{7}$ Например, реплика Бойе: “Proud of employment, willingly I go” (II, 1; Viv = 1,24).
} 
Как и любая платформа, VVV привлекает внимание к ранее незамеченным моментам сходства и различия переводов и одновременно ограничивает круг обзора текстов. Мастерство филолога - в том, чтобы не стопроцентно доверять этой свободе и уметь преодолевать сковывающие ограничения.

\section{СПИСОК ЛИТЕРАТУРЫ}

Азов, А. Г. (2013) Поверженные буквалисты : Из истории художественного перевода в СССР в 1920-1960-е годы. М. : Изд. дом Высшей школы экономики. $304 \mathrm{c}$.

Гаспаров, М. Л. (1971) Брюсов и буквализм (По неизданным материалам к переводу «Энеиды») // Мастерство перевода. Вып. 8. М. : Советский писатель. 488 c. C. 88-128.

Гаспаров, М. Л. (2003) Экспериментальные переводы. СПб. : Гиперион. 347, [5] c.

Гаспаров, М. Л., Автономова, Н. С. (2001) Сонеты Шекспира - переводы Маршака // Гаспаров М. Л. О русской поэзии : Анализы. Интерпретации. Характеристики. СПб. : Азбука. 476, [2] с. С. 389-409.

Сонькин, В. В., Борисенко, А. Л. (2010) Гаспаров-переводовед и Гаспаровпереводчик // Иностранная литература. № 12. С. 192-200.

Шекспир, В. (1873) Драматические сочинения В. Шекспира : в 9 ч. / перев. (в прозе) Н. Кетчера, выправленный и пополненный по найденному Пэн Колльером старому экземпляру in folio 1632 г. [2-е изд.]. М. : Изд. Солдатенкова и Щепкина. Ч. 7: Крещенская ночь ; Гамлет ; Тщетный труд любви ; Мера за меру. [4], 433 с. (37 вып.).

Шекспир, В. (1894) Полн. собр. соч. в прозе и стихах : в 12 т. / перев. (в прозе) П. А. Каншина ; биогр. очерк Н. И. Стороженко ; примеч. П. И. Вейнберга и др. СПб. : Изд. Добродеева. Т. 12: Напрасный труд любви ; Все хорошо, что кончается хорошо ; Как вам угодно ; Два благородных родственника ; Завещание. 365 с.

Шекспир, В. (1899) Бесплодные усилия любви. Комедия в пяти действиях / пер. П. И. Вейнберга // Шекспир В. Полн. собр. соч. Виллиама Шекспира в переводе русских писателей : в 3 т. / под ред. Д. Л. Михаловского. 5-е изд. СПб. : Изд. Н. В. Гербель. Т. 1. 601, [2] с. С. 255-303.

Шекспир, В. (1937) Бесплодные усилия любви / пер. М. А. Кузмина // Шекспир В. Полн. собр. соч. : в 8 т. / под общ. ред. С. С. Динамова, А. А. Смирнова. М. ; Л. : Academia. Т. 1. VIII, 771 c. С. 5-141. 
Шекспир, В. (1945) Бесплодные усилия любви / перев. К. И. Чуковского. М. : ВУОАП. 59 с.

Шекспир, У. (1958) Бесплодные усилия любви / пер. Ю. Б. Корнеева // Шекспир У. Полн. собр. соч. : в 8 т. / под общ. ред. А. А. Смирнова, А. А. Аникста. М. : Искусство. Т. 2.548 с. С. 393-512.

Brownlie, S. (2006) Narrative theory and retranslation theory // Across Languages and Cultures. Vol. 7. No. 2. P. 145-170. DOI: 10.1556/Acr.7.2006.2.1

Cheesman, T., Flanagan, K., Thiel, S. (2012-2013) Translation array prototype 1: Project overview [Электронный pecypc] // Version Variation Visualization. URL: http://delightedbeauty.org/vvv/Home/Project [архивировано в WaybackMachine] (дата обращения: 10.12.2017).

Cheesman, T. et al. (2017) Multi-retranslation corpora: Visibility, variation, value and virtue / T. Cheesman, K. Flanagan, S. Thiel, J. Rybicki, R. S. Laramee, J. Hope, A. Roos // Digital Scholarship in the Humanities. Vol. 32. Issue 4. P. 739-760. DOI: 10.1093/llc/fqw027

Cheesman, T., Roos, A. (2017) Version Variation Visualization (VVV): Case studies on the Hebrew Haggadah in English [Электронный ресурс] // Journal of Data Mining and Digital Humanities. Special issue on computer-aided processing of intertextuality in ancient languages. URL: https://jdmdh.episciences.org/3737/pdf [архивировано в WaybackMachine] (дата обращения: 10.12.2017).

Delabastita, D. (2011) Literary translation // Handbook of translation studies / ed. by Y. Gambier, L. van Doorslaer Vol. 2. Amsterdam : John Benjamins Publishing Company. x, 197 p. P. 69-78.

Draudt, M. (1982) The "Rosaline-Katherine Tangle” of Love's Labour's Lost // The Library. Vol. s6-IV. Issue 4. P. 381-396. DOI: 10.1093/library/s6-IV.4.381

Fernández Guerra, A. (2000) Machine translation. Capabilities and limitations. Valencia : Universitat de València. 159 p.

Jianzhong, X. (2003) Retranslation: necessary or unnecessary // Babel. Vol. 49. No. 3. P. 193-202. DOI: 10.1075/babel.49.3.02jia

Kerrigan, J. (1982a) Love's Labour's Lost and Shakespearean revision // Shakespeare. Quarterly. Vol. 33. No. 3. P. 337-339. DOI: $10.2307 / 2869738$

Kerrigan, J. (1982b) Shakespeare at work: The Katherine-Rosaline tangle in Love's Labour's Lost // Review of English Studies. Vol. 33. No. 130. P. 129-136.

Love's Labour's Lost: Introduction (2017) // The New Oxford Shakespeare : The complete works : Critical reference edition : [in 2 vols.] / ed. by G. Taylor, J. Jowett, T. Bourus, G. Egan. [Oxford] : Oxford University Press. Vol. 1. xcvii, 1516 p. P. 449461. 
Paloposki, O., Koskinen, K. (2004) A thousand and one translations: Revisiting retranslation // Claims, changes and challenges in translation studies: Selected contributions from the EST Congress, Copenhagen 2001 / ed. by G. Hansen, K. Malmkjær, D. Gile. Amsterdam ; Philadelphia : John Benjamins. xiii, 318 p. P. 27-38. (Benjamins Translation Library. Vol. 50). DOI: 10.1075/btl.50.04pal

Shakespeare, W. Love's Labor's Lost / ed. by B. A. Mowat, P. Werstine [Электронный ресурс] // Folger Digital Texts. URL: http://folgerdigitaltexts.org/? chapter=5\&play=LLL [архивировано в WaybackMachine] (дата обращения: 10.12. 2017).

Voigt, R., Jurafsky, D. (2012) Towards a literary machine translation: The Role of referential cohesion // Proceedings of the NAACL-HLT 2012 Workshop on Computational Linguistics for Literature. P. 18-25. URL: https://stanford.edu/ jurafsky/ voigtjurafsky12.pdf [архивировано в WaybackMachine] (дата обращения: 10.12. 2017).

Дата поступления: 13.12.2017 2.

Макаров Владимир Сергеевич — кандидат филологических наук, доцент кафедры германской филологии Православного Свято-Тихоновского гуманитарного университета. Адрес: 109651, Россия, г. Москва, ул. Иловайская, д. 9, корп. 2. Тел.: +7 (495) 646-71-38. Эл. адрес: mail@vmakarov.name

Makarov Vladimir Sergeevich, Candidate of Philology, Associate Professor, Department of Germanic Philology, St. Tikhon's Orthodox University. Postal address: Bldg. 2, 9 Ilovaiskaya St., 109651 Moscow, Russian Federation. Tel.: +7 (495) 646-7138. E-mail: mail@vmakarov.name

\section{Для изитирования:}

Макаров В. C. «Бесплодные усилия любви» в русских переводах: опыт сравнительного анализа [Электронный ресурс] // Горизонты гуманитарного знания. 2017. № 6. C. 85-102. URL: http://journals.mosgu.ru/ggz/article/view/642 (дата обращения: дд.мм.гггг). DOI: 10.17805/ggz.2017.6.6 